Volume 19, No 3 International Journal of Radiation Research, July 2021

\title{
Evaluation of radon concentration and natural radioactivity exposure from the soil of Wadi Hodein region, Egypt
}

\author{
E.H. EL-Araby', D.H. Shabaan ${ }^{2,3^{*}}$, Z. Yousef3 \\ ${ }^{1}$ Department 1Physics Department, Faculty of Science, Jazan University, 2097 Jazan, Saudi Arabia \\ 2Physics Department, University College of Samtah, Jazan University, Jazan, Saudi Arabia \\ ${ }^{3}$ Physics Department, Faculty of Women for Art, Science and Education, Ain Shams University, Cairo, Egypt
}

\section{- Original article}

*Corresponding authors:
Doaa H. Shabaan, Ph.D.,
E-mail:
doaa.hassantaha@women.asu.edu.eg
Revised: July 2020
Accepted: August 2020
Int. J. Radiat. Res., July 2021;
19(3): 719-727
DOI: $10.29252 /$ ijrr.19.2.719

\begin{abstract}
Background: The presence of radon and radioactive nuclei emitted from uranium could result in a radiological hazard. Humans are exposed to natural radiation, which arises from cosmic radiation, radon gas, and radiation from radioactive nuclei of each thorium, uranium, and thorium. Methods and Methods: This research cares to study the concentration of the natural radioactivity (238-U, 232-Th and 40-K) and radon for fourteen samples of soil from different fourteen location in Wadi Hodein region in Egypt (Southern Eastern Desert). The radon gas was measured using CR-39 detector, while the activity concentration for natural radioactivity measured by HPGD system. Results: The results of the gamma ray spectroscopy show that main activity concentration of $238-\mathrm{U}, 232-\mathrm{Th}$ and $40-\mathrm{K}$ are $13.04 \pm 1.15,12.33 \pm 1.54$ and $445.33 \pm 23.54 \mathrm{~Bq} / \mathrm{Kg}$ respectively. The $43 \%$ form concentration value for $\mathrm{K}-40$ are higher than the exemption level $412 \mathrm{~Bq} / \mathrm{Kg}$ proposed by the UNSCEAR 2008. Moreover, the $15 \%$ of values for absorbed dose $D_{a b}$ were higher than public average $57 \mathrm{nGy} / \mathrm{h}$. But annul effective dose values AED were less than recommended limits for the radiation which reported by UNSCEAR 2000 and 2008. The mean value concentration of radon was $265.96 \pm 25.45 \mathrm{~Bq} / \mathrm{m}^{3}$. The results of samples show that $28.27 \%$ of the radon gas concentrations and annul effective dose from radon $\left(A E D_{R}\right)$ in soil is higher than allowed limit recommended from International Commission on Radiological Protection agency (ICRP 2007). Conclusions: Radium, shows good relationship with radon exhalation rate in soil. Good correlation observed between lung cancer per year per million people and radon concentrations for all soil samples.
\end{abstract}

Keywords: Radiological hazard, natural radioactivity, SSNTDS, HPGD.

\section{INTRODUCTION}

CR-39 plastic detector is one of the most popular radiation detection, because its high sensitivity to protons and alpha particles (1), CR-39 is used in many fields that contribute to the detection of radioactive materials, including radon gas, which is one of the most dangerous radioactive materials since it is a gas, tasteless and odorless (2).

Radon ${ }^{222} \mathrm{Rn}$ is a noble element produced from the terrestrial elements uranium isotopes
${ }^{238} \mathrm{U},{ }^{235} \mathrm{U}$ and ${ }^{232} \mathrm{Th}$.The molecules of radon gas diffuse out through pore spaces in soils and rocks and mix with the atmosphere. The radon gas has three isotopes, ${ }^{222} \mathrm{Rn}$ resulted by the decay of ${ }^{238} \mathrm{U}$ series, ${ }^{220} \mathrm{Rn}$ resulted by the decay of ${ }^{232} \mathrm{Th}$ series and ${ }^{219} \mathrm{Rn}$ a decay produced from the chain originating with U-235 (3). Inhalation of radon gas leads to lung cancer and this occurs in the unventilated environments where the concentration of gas and its daughters increases.

Literature review, from previous studies, it claims that radon gas concentration in soil 
effects on humans, plants and animals. It is measured in different places such as: Saudi Arabia (4), Bulgaria (5) and Egypt (6). Radon rates of entry into pore spaces are clearly important to determining and then into atmosphere and the radon rates depend on the concentration of radium in the bedrock and on the permeability of the soil (7.8). During decay of Radium, radon gas is formed. Long exposure time Radon and his daughters will cause health changes in respiratory functions that may result lung cancer ${ }^{(9)}$.

The activity levels of ${ }^{238 \mathrm{U}},{ }^{232} \mathrm{Th}$ and ${ }^{40} \mathrm{~K}$ obtained in the current study were compared with the results of the literature as shown in Table 3 for soil samples in different countries. Moreover, a comparison has been made between the results of the current study and other studies in Egypt.

New studies have shown that the emanation of radon from the soil is dangerous to human health. The UK Health Agency report shows that radon gives higher doses of radiation than any other source (10). WHO data on radon indicate that 3 to 16 percent of lung cancers are caused by internal radon.

Natural radioactivity (Uranium, Thorium and Potassium) are associated with a huge variety of stones and is mainly due to the supplement minerals they contain. Always human have been exposed to natural ionizing radiation, called extraterrestrial and terrestrial radiation $(11,12)$. Extraterrestrial origin of radiation is about 30 $\mathrm{nGyh}^{-1}$, while that of terrestrial origin is due to the presence of naturally occurring radionuclides; mainly potassium, rubidium and the radionuclides in the decay chains of thorium and uranium (2).

Ornamental stone is mined by underground and surface mining operations. Decorative stone is used in the decoration work for floors and walls. Therefore, scientists pay great attention to the study of the environment surrounding the places of extracting ornamental stones. Pollution by radioactive atoms that comes from decay of ${ }^{238} \mathrm{U},{ }^{232} \mathrm{Th}$ and ${ }^{40} \mathrm{~K}$ is monitored in order to preserve the environment and public health (1318).

The aim of this study is to calculate radon concentration and exhalation rates of radon using the CR-39 detector in some kinds of ornamental stones from Wadi Hodein area, Egypt and for the same samples determine the natural radioactivity of ${ }^{238} \mathrm{U},{ }^{232} \mathrm{Th},{ }^{226} \mathrm{Ra}$ and ${ }^{40} \mathrm{~K}$ by using HPGD. These results are of great interest in the study of environmental radiation protection, where marble and granite are widely used as building materials and decorations, including the inner cover.

\section{MATERIALS AND METHODS}

\section{The study area}

The Wadi Hodein area contains a variety wide of late Precambrian igneous and metamorphic rocks, represented by gneisses, serpentinites, metagabbros, metasediments, metavolcanics, metagabbro-diorite, granodiorite and granitoids. The Wadi Hodein metavolcanics (WHV), including G. Khashab and G. El Anbat, appear for one of the significant metavolcanic suites in the southern part of the Nubian Shield. The Wadi Hodein area is located in the southern extremity of the south Eastern Desert of Egypt and some $20 \mathrm{~km}$ west of Shalatin at the Red Sea coast. It is bounded by Latitudes $23^{\circ} 30$ to $23^{\circ}$ $50 \mathrm{~N}$ and longitude $35^{\circ} 30$ to $35^{\circ} 41 \mathrm{E}$ covering area about $200 \mathrm{~km}^{2}$ (figure 1). There are many activities in Wadi Hodein area, such as the reclamation and cultivation of large areas of the valley lands and the establishment of poultry farms and towers for breeding pigeons, to be an urban agricultural community. Therefore, it is important to study the area radio logically to make sure it is free from any radiation danger.

\section{Alpha measurement}

At this time, 14 samples of soil were collected from (Wadi Hadin area in the South Eastern Desert of Egypt). Samples were prepared, weighed, and placed in a plastic room for a period of not less than a month, to obtain a radiation balance. A sheet of The CR-39 detector TASTRAK type, (Track Analysis System, Ltd., UK) is cut into a square whose side is $1.5 \mathrm{~cm}$ long. This detector features high sensitivity, optical transparency uniformity and uniformity on

Int. J. Radiat. Res., Vol. 19 No. 3, July 2021 
cylindrical cans used to monitor radon gas at the height of $8 \mathrm{~cm}$ from the soil. These cans were closed and stored for thirty days. Then the exposed detectors (CR-39) were collected and chemically etched by $\mathrm{NaOH}$ at $70{ }^{\circ} \mathrm{C}$ for six hours. The track densities (track/cm) on CR-39 detector were counted using the optical microscope $(4,19,20)$.

The track density was used to determine the radon concentration $\mathrm{C}\left(\mathrm{Bq} / \mathrm{m}^{3}\right)$ according to the equation $1(1,4,21,22)$ :

$C=\frac{\rho}{K t}$

Where; $t$ is the time exposure, and $\mathrm{K}$ is the calibration factor for SSNTDs can be determined by the standard $\mathrm{Rn}$-chamber $\mathrm{K}=0.045987 \mathrm{~cm}^{-2}$ $\mathrm{d}^{-1} / \mathrm{Bqm}^{-3}$ pathways of radon (23).The equilibrium radon concentration $\mathrm{C}_{\text {eq }}\left(\mathrm{Bq} / \mathrm{m}^{3}\right)$ is given by the effective exposure time $\mathrm{T}_{\mathrm{e}}$ and is calculated using the equation 2 :

$C_{e q}=\frac{C_{i}}{T_{E}}=\frac{\rho}{K T_{e}}$

Where; $T_{s}=t-\frac{1-e^{-\lambda t}}{\lambda}, \lambda$ is the constant decay of radon and $\mathrm{C}_{\mathrm{i}}\left(\mathrm{Bqm}^{-3} . \mathrm{d}\right)$ is the radon concentration integration. The surface exhalation rate $\left(\mathrm{mBqm}^{-2} \cdot \mathrm{h}^{-1}\right)$ of the sample for the release of radon can be calculated by the equation 3 exhalation rate:

$\mathrm{E}_{\mathrm{a}}=\frac{\mathrm{C}_{\mathrm{i}} \mathrm{V \lambda}}{\mathrm{A} \mathrm{T}_{\mathrm{e}}}$

Where $A$ is the area of cup $\left(\mathrm{m}^{2}\right), V$ is the effective volume of the cup in $\mathrm{m}^{3}, \lambda$ the decay constant for radon in $\mathrm{h}^{-1}$, and $T$ the exposure time in hours.

The exhalation rate of mass $\left(\mathrm{mBqkg}^{-1} \cdot \mathrm{h}^{-1}\right)$ in the samples is measured using the equation 4 (4, 23-25):

$\mathrm{E}_{\mathrm{m}}=\frac{\mathrm{C}_{\mathrm{i}} \mathrm{V} \lambda}{\mathrm{MT}_{\mathrm{e}}}$

Where; $M$ is the sample mass $(\mathrm{kg}) \mathrm{m}$

The radium content effective $\mathrm{Ra}_{\text {eff }}(\mathrm{Bq} / \mathrm{Kg})$ is calculated using the relation $(5)(4,18,24)$ :

$\mathrm{Ra}_{\mathrm{eff}}=\frac{\mathbf{E}_{\mathrm{m}}}{\lambda}$

Int. J. Radiat. Res., Vol. 19 No. 3, July 2021
The annual effective dose was calculated by using three factors, which are the dose conversion factor $\mathrm{D}\left(9 \mathrm{nSv} / \mathrm{hr} / \mathrm{bq} / \mathrm{m}^{3}\right)$ and the internal balance factor of radon and its sons $\mathrm{F}$ (0.4) and the value of time during the year that passes through exposure to radon gas (8760 hy $^{-1}$ ). The equation 6 is used to determine the annual effective dose rate (mSv/year) (2):

$\mathrm{AED}_{\mathrm{R}}=\mathrm{C} \times \mathrm{D} \times \mathrm{F} \times \mathrm{T}$

The lung cancer cases per year per million person (CPPP), was obtained using the equation 7 (23-26):

$(\mathrm{CPPP})=\mathrm{AED}_{\mathrm{R}} \times\left(18 \times 10^{-6} \mathrm{mSv}^{-1} \cdot \mathrm{y}\right)$

\section{Gamma measurement}

The solid samples for gamma activity analysis we prepare $100 \mathrm{cc}$ from each sample and placed in a polyethylene container, these were completely sealed, weighed, and were left for at least one month to allow radioactive equilibrium. A coaxial hyper pure Ge detector with volume $76.11 \mathrm{~cm}^{3}$ is made of highly pure Germanium crystal, model GMX 60P4 and its electronic circuits. Crystalline dimensions are $69.5 \mathrm{~mm}$ in diameter and $86.7 \mathrm{~mm}$ in length. Its relative effectiveness is $60 \%$ peak to Compton 56: 1 . FWHM at $1.33 \mathrm{MeV}$ of ${ }^{60} \mathrm{Co}$ is $2.3 \mathrm{kV}$, and $1.10 \mathrm{kV}$ at $5.9 \mathrm{kV}$ from $55 \mathrm{Fe}$. Collected spectra are analyzed using the ORTEC Maestro software package with the other measuring components in a singles gamma ray spectrometer and a Maestro, H-EG\&G ORTEC MCA card mounted on an IBM compatible PC together with simple programs to estimate quantitatively the elements present in the samples under investigation. The absolute efficiency calibration curve for the spectrometer was carried out together with the energy calibration. To reduce the background radiation the detector was placed surrounded by a lead cylindrical shield lined with a copper layer inside it and covered with a movable cover. The back ground was monitored to be taken in consideration. The $\gamma$ ray energy transition used to measure the $\mathrm{U}$ concentration, Th and $\mathrm{K}$ was calculated using the different gamma transitions of every isotope 
present and the average values are given.

The gamma spectra, for the different samples were collected for at least twenty four hours, the back ground was taken in consideration when the quantitative calculations of the uranium, thorium and potassium were made.

The equivalent Radium activity is a widely used hazard index. It is determined by equation 8, (27, 28, 7):

$\mathrm{Ra}_{\mathrm{eq}}=\mathrm{A}_{\mathrm{Ra}}+1.43 \mathrm{~A}_{\mathrm{Th}}+0.077 \mathrm{~A}_{\mathrm{K}}$

Where; $A_{R a}$ is the activity of ${ }^{226} \mathrm{Ra}, \mathrm{A}_{\mathrm{Th}}$ is the activity of ${ }^{232} \mathrm{Th}$ and $A_{K}$ is the activity of ${ }^{40} \mathrm{~K}$, in $\mathrm{Bq} / \mathrm{kg}$.

\section{The hazardous parameters of radiation}

There are two important parameters external hazard radiation and internal radiation hazard obtained from $\mathrm{Ra}_{\mathrm{eq}}$ expression through the proposition. The maximum value of these parameters must be equal to the unity in order to reduce the risk of radiation. The external hazard index $\left(\mathrm{H}_{\mathrm{ex}}\right)$ is given by the equation 9:

$H_{e x}=\frac{A_{R a}}{370}+\frac{A_{T h}}{259}+\frac{A_{K}}{4810}$

Where $\left(H_{e x} \leq 1\right)$ is external hazard index. $A_{R a}$, $A_{T h}$ and $A_{K}$ are the activity concentrations, expressed in $(\mathrm{Bq} / \mathrm{kg})$ for radium, thorium and potassium respectively. The internal hazard index $\left(\mathrm{H}_{\text {in }}\right)$ gives the internal exposure to carcinogenic radon and its short-lived progeny and is giving by the equation 10 (27):

$H_{e x}=\frac{A_{R a}}{185}+\frac{A_{T h}}{259}+\frac{A_{K}}{4810}$

Where; $\left(H_{\text {in }} \leq 1\right)$ is internal hazard index. The $A_{\text {Ra }}, A_{T h}$ and $A_{K}$ are the activity concentrations, expressed in $(\mathrm{Bq} / \mathrm{kg})$ for radium, thorium and potassium respectively.

The dose conversion factors $\mathrm{F}$ are used to convert the activity concentrations of $238 \mathrm{U}$ series, ${ }^{232} \mathrm{Th}$ series and ${ }^{40} \mathrm{~K}$ into doses (nGy/h per $\mathrm{Bq} / \mathrm{kg}$ ) as 0.427, 0.662 and 0.043 , respectively. The absorbed dose rate $\mathrm{D}(\mathrm{nGy} / \mathrm{h})$ is calculated for each radionuclide using equation 11:
$\mathrm{Dab}=0.462 \mathrm{~A}_{\mathrm{Ra}}+0.604 \mathrm{~A}_{\mathrm{Th}}+0.0417 \mathrm{~A}_{\mathrm{k}}$

The annual effective dose AED (mSv/y) in air outdoors was measured by conversion factor $F$ of $0.7 \times 10-6 \mathrm{~Sv} /$ Gy and calculated by equation 12 $(28,7)$ :

$\mathrm{AED}=\mathrm{Dab} \times \mathrm{T} \times \mathrm{F}$

Where: $T$ is the outdoor occupancy time $(0.2 \times 24$ $\mathrm{h} \times 365.25 \mathrm{~d}=1753 \mathrm{~h} / \mathrm{y}$ ).

The radiation level index of gamma radiation hazard (I $\gamma$ ) associated with the natural radionuclides. It is assessed by the European Commission (EC), which should be lesser than unity ${ }^{(27)}$ and calculated by equation 13 :

$I_{Y}=\frac{A_{R a}}{150}+\frac{A_{T h}}{100}+\frac{A_{K}}{1500}$

I $\gamma$ May be used to estimate the level of $\gamma$ radiation hazard associated with natural radionuclides in the soil used.

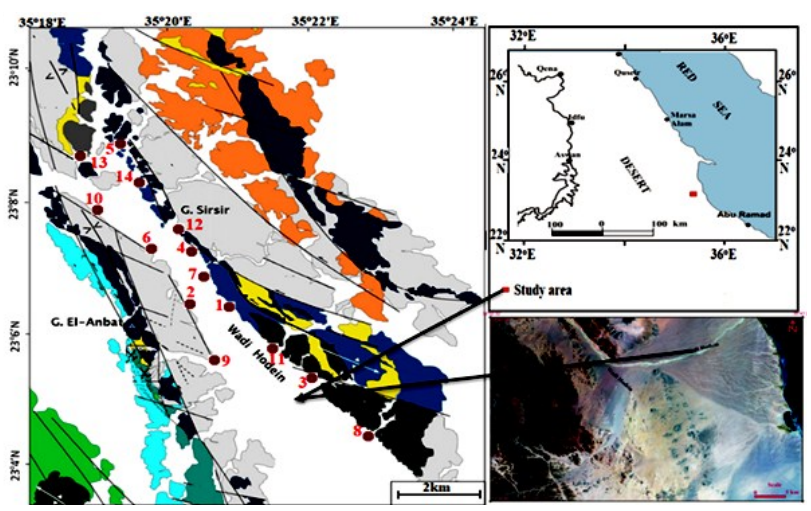

Figure 1. The Wadi Hodein map of the sampling points.

\section{RESULTS}

\section{Measurements of Gamma by using HPGD}

The concentrations gamma activity of solid samples collected from Wadi Hodein in the southern Eastern Desert of Egypt were measured by HPGD. This activity depends on the gamma ray emitted from radioactive nuclei in the sample. The activity concentration of ${ }^{226} \mathrm{Ra}$ and 222Rn daughter are listed in table 1 for all sample and show that the activity of Ra-226 is ranged from 6.37 to $26.27 \mathrm{~Bq} / \mathrm{Kg}$ with main 
value $12.88 \pm 0.29 \mathrm{~Bq} / \mathrm{Kg}$. The activity range of radon daughter $\mathrm{Pb}-214$ and $\mathrm{Bi}-214$ are from 6.72 to $25.57 \mathrm{~Bq} / \mathrm{Kg}$ and from 6.59 to $25.26 \mathrm{~Bq} /$ $\mathrm{Kg}$, respectively. The mean value of radon concentration of is $13.09 \pm 1.15 \mathrm{~Bq} / \mathrm{Kg}$.

The activity concentrations for ${ }^{238} \mathrm{U},{ }^{232} \mathrm{Th}$ and ${ }^{40} \mathrm{~K}$ are presented in table 1 . The results show that the concentration of ${ }^{238} \mathrm{U},{ }^{232} \mathrm{Th}$ and ${ }^{40} \mathrm{~K}$ ranged from 6.64 to 25.50 , from 6.62 to 26.30 and from 183.94 to $945 \mathrm{~Bq} / \mathrm{kg}$ respectively. The average concentration for $238 \mathrm{U}$, ${ }^{232} \mathrm{Th}$ and ${ }^{40} \mathrm{~K}$ were $13.04 \pm 1.1512 .33 \pm 1.54$ and $445.33 \pm 23.54 \mathrm{~Bq} / \mathrm{Kg}$, respectively.

Concerning the values of the equivalent radium $\left(\mathrm{Ra}_{\mathrm{eq}}\right)$ were ranged from $30.22 \pm 2.12 \mathrm{~Bq} /$ $\mathrm{kg}$ to $140.26 \pm 6.55 \mathrm{~Bq} / \mathrm{kg}$, with a mean value of $66.36 \pm 9.89 \mathrm{~Bq} / \mathrm{kg}$. The value of absorbed dose $\mathrm{D}_{\mathrm{ab}}$ varies from $14.82 \pm 1.04$ to $69.45 \pm 4.24 \mathrm{nGy} / \mathrm{h}$ with an average value of $32.86 \pm 2.64 \mathrm{nGy} / \mathrm{h}$. the $15 \%$ of these values of absorbed dose $D_{a b}$ are higher than the public average $57 \mathrm{nGy} / \mathrm{h}{ }^{(8)}$. The annual effective dose (AED) was found that in the range $0.02 \pm 0.001$ to $0.09 \pm 0.01 \mathrm{mSv}$ with mean value $0.04 \pm 0.003 \mathrm{mSv}$. All values of AED were lower than the recommended limits for the radiation which reported by UNSCEAR $(7,8)$ (for public is $1 \mathrm{mSv} / \mathrm{y}$ and for worker $5 \mathrm{mSv} / \mathrm{y}$ ).

According to report of UNSCEAR $(29,7)$ the representative gamma index $(\mathrm{I} \gamma)$, internal hazard index $\left(\mathrm{H}_{\text {in }}\right)$ and external hazard index $\left(\mathrm{H}_{\mathrm{ex}}\right)$ should be less than or equal one. The result shows that the mean value of the representative gamma index (I $\gamma)$, internal hazard index (Hin) and external hazard index $\left(\mathrm{H}_{\mathrm{ex}}\right)$ were $0.24 \pm 0.02$, $0.22 \pm 0.02$ and $0.04 \pm 0.003$ respectively. All values of them were less than the recommended values.

\section{The measurement of radon by using CR-39}

The radon concentration related their type of soil samples combined from Wadi Hodein in the southern Eastern Desert of Egypt are shown in figure 2. The concentration of radon varied from $777.22 \pm 49.83 \mathrm{~Bq} / \mathrm{m}^{3}$ in $\mathrm{H}_{8}$ to $26.28 \pm 9.53 \mathrm{~Bq} / \mathrm{m}^{3}$ in $\mathrm{H}_{2}$ with an average value of $265.96 \pm 25.45 \mathrm{~Bq} /$ $\mathrm{m}^{3}$. It is shown from the results that the concentration of radon changes appreciably in different samples. It is since the samples of soil collected from different sites may have appreciably large uranium contents which results in higher radon emanation rates. The results of samples show that $71.42 \%$ of the radon gas concentrations in soil is below the allowed limit while $28.57 \%$ of radon concentration were larger than the limited recommended from (ICRP) agency which is (200 $\left.\mathrm{Bq} / \mathrm{m}^{3}\right)(30,31)$.

The annual effective dose has maximum value $24.42 \pm 1.57 \mathrm{mSv} / \mathrm{y}$ in sample $\mathrm{H} 8$ with mean value $8.39 \pm 0.80 \mathrm{mSv} / \mathrm{y}$ (figure 3). The results show that $28.57 \%$ of AED were higher than the allowable limits recommended from ICRP agency which is $(3-10 \mathrm{mSv} / \mathrm{y})(30,25)$.

Table 4 summarizes the results of rate of exhalation for radon in soil, lung cancer cases per year per million person (CPPP) and the concentration of Radium. It can be seen from the results that the radon exhalation rate varies from $79.25 \pm 5.10 \mathrm{mBq} / \mathrm{m}^{2} . \mathrm{h}, 4.98 \pm 0.32 \mathrm{mBq} / \mathrm{Kg}$. h to $2.69 \pm 0.98 \mathrm{mBq} / \mathrm{m}^{2}$.h, $0.17 \pm 0.06 \mathrm{mBq} / \mathrm{Kg} . \mathrm{h}$ with a mean value $27.22 \pm 2.60 \mathrm{mBq} / \mathrm{m} 2 . \mathrm{h}$, $1.71 \pm 0.16 \mathrm{mBq} / \mathrm{Kg}$. $\mathrm{h}$. The results showed that the radium values detected in the samples were within the permissible limits, which is the internationally recorded safe limit $\left(370 \mathrm{~Bq} \mathrm{~kg}^{-1}\right)$ $(7,8)$. The highest measured radium value was $67.10 \pm 4.32 \mathrm{~Bq} / \mathrm{Kg}$ in the sample $\mathrm{H} 8$ and the average value has $23.05 \pm 2.21 \mathrm{~Bq} / \mathrm{Kg}$. Also, the radium values were within the limit's values measured in the soil of India are (207.00 - 2.50 $\mathrm{Bq} / \mathrm{kg}$ ) (32). The measured radon exhalation rates were clearly correlated with samples. It is evidence of a change in the concentration of uranium from one sample to another.

The lung cancer cases per year per million person (CPPP) in different sample were yielded from $439.49 \pm 28.29$ to $14.92 \pm 5.41$ with average value $150.97 \pm 14.44$ per million persons. The results indicated that $\mathrm{H} 4$ and $\mathrm{H} 8$ were higher than the internationally permitted limit, while the rest of the samples were less than the permissible limit of $230-170$ per million people recommended by (33).

\section{Comparison of present study with other studies}

The activity levels of ${ }^{226} \mathrm{Ra}-,{ }^{232} \mathrm{Th}-$ and ${ }^{40} \mathrm{~K}$ obtained in the current study were compared 
with the results of the literature as shown in table 3 for soil samples in different countries. Moreover, a comparison has been made between the results of the current study and other studies in Egypt. There is a difference between the values shown in the table, depending on the different concentration of radioactive nuclei from one place to another. The mean of the results values in the current study was in agreement with most of the results shown in table 3.

Table 1. The concentration of radioactive level for different radioactive nuclei of different collected sample.

\begin{tabular}{|c|c|c|c|c|c|c|c|}
\hline \multirow{4}{*}{$\begin{array}{l}\text { Radioactive elements } \\
\text { Energy of gamma KeV }\end{array}$} & \multicolumn{4}{|c|}{ Activity concentration of Uranium $(\mathrm{Bq} / \mathrm{Kg})$} & \multirow{3}{*}{\multicolumn{3}{|c|}{ Average Activity $\mathrm{Bq} / \mathrm{Kg}$}} \\
\hline & \multirow{3}{*}{$\begin{array}{c}\text { Ra-226 } \\
186\end{array}$} & \multicolumn{3}{|c|}{ Daughter of Rn-222 } & & & \\
\hline & & \multirow{2}{*}{$\begin{array}{c}\mathrm{Pb}-214 \\
352\end{array}$} & \multirow{2}{*}{$\begin{array}{c}\mathrm{Bi}-214 \\
609\end{array}$} & \multirow{2}{*}{$\begin{array}{c}\text { Bi-214 } \\
1765\end{array}$} & & & \\
\hline & & & & & U-238 & Th-232 & K-40 \\
\hline H1 & $7.08 \pm 0.12$ & $7.73 \pm 0.43$ & $7.33 \pm 0.34$ & $6.59 \pm 0.32$ & $7.18 \pm 0.48$ & $7.54 \pm 0.32$ & $203.27 \pm 8.66$ \\
\hline $\mathrm{H} 2$ & $6.37 \pm 0.05$ & $6.72 \pm 0.12$ & $6.89 \pm 0.20$ & $6.59 \pm 0.06$ & $6.64 \pm 0.22$ & $6.62 \pm 0.58$ & $183.94 \pm 16.10$ \\
\hline H3 & $7.88 \pm 0.05$ & $7.86 \pm 0.23$ & $7.76 \pm 0.21$ & $7.46 \pm 0.05$ & $7.74 \pm 0.19$ & $79 \pm 0.15$ & $213.00 \pm 3.97$ \\
\hline H4 & $13.29 \pm 0.53$ & $15.69 \pm 1.37$ & $18.48 \pm 0.97$ & $15.83 \pm 0.87$ & $15.82 \pm 2.12$ & $10.24 \pm 1.35$ & 4.42 \\
\hline H5 & $8.25 \pm 0.13$ & $9.01 \pm 0.44$ & $8.56 \pm 0.36$ & $7.78 \pm 0.23$ & $8.40 \pm 0.52$ & $79 \pm 0.07$ & 1.80 \\
\hline H6 & 8.64 & 0.27 & $8.12 \pm 0.21$ & .08 & $44 \pm 0.33$ & .59 & 203.3 \\
\hline H7 & $9.07 \pm 0.08$ & $9.68 \pm 0.05$ & $9.73 \pm 0.08$ & $9.76 \pm 0.07$ & $9.56 \pm 0.33$ & $11.24 \pm 0.24$ & \pm 4.88 \\
\hline H8 & $26.24 \pm 0.79$ & $19.33 \pm 2.83$ & $23.85 \pm 3.03$ & $25.94 \pm 0.98$ & $23.84 \pm 3.38$ & $27.73 \pm 3.89$ & 945.0 \\
\hline H9 & $13.29 \pm 1.13$ & $13.83 \pm 3.33$ & $16.31 \pm 3.04$ & $23.18 \pm 1.41$ & $16.65 \pm 4.84$ & $18.44 \pm 1.01$ & $390.00 \pm 21.3$ \\
\hline H10 & $11.95 \pm 0.22$ & $12.05 \pm 1.32$ & $11.13 \pm 1.02$ & $9.66 \pm 0.35$ & $11.20 \pm 1.21$ & $12.53 \pm 0.61$ & $254.79 \pm 12.43$ \\
\hline H11 & $26.27 \pm 0.15$ & $25.57 \pm 0.34$ & $25.26 \pm 0.37$ & $24.91 \pm 0.14$ & $25.50 \pm 0.33$ & $26.30 \pm 0.69$ & $570.00 \pm 14.85$ \\
\hline H12 & $21.63 \pm 0.37$ & $18.28 \pm 1.78$ & $21.08 \pm 0.93$ & $21.58 \pm 0.68$ & $20.64 \pm 1.78$ & $24.02 \pm 1.81$ & $891.00 \pm 67.10$ \\
\hline H13 & $12.19 \pm 0.23$ & $13.51 \pm 0.70$ & $14.45 \pm 0.41$ & $13.04 \pm 0.63$ & $13.30 \pm 0.72$ & $7.21 \pm 1.50$ & $738.00 \pm 53.88$ \\
\hline H14 & $8.25 \pm 0.14$ & $7.24 \pm 0.26$ & $7.22 \pm 0.09$ & $7.67 \pm 0.18$ & $7.60 \pm 0.25$ & $7.53 \pm 0.40$ & $212.49 \pm 11.22$ \\
\hline Range & $6.37-26.27$ & $6.72-25.57$ & $6.89-25.26$ & $6.59-24.91$ & $6.64-25.50$ & $6.62-26.30$ & $183.94-945$ \\
\hline average & $12.88 \pm 0.29$ & $12.52 \pm 0.96$ & $13.29 \pm 0.80$ & $13.44 \pm 0.43$ & $13.04 \pm 1.15$ & $12.33 \pm 1.01$ & $445.33 \pm 17.07$ \\
\hline
\end{tabular}

Table 2. The activity concentration for $\mathrm{U}-238$, Th- 232 and $\mathrm{K}-40 \mathrm{~Bq} / \mathrm{kg}$.

\begin{tabular}{|c|c|c|c|c|c|c|}
\hline \multirow{2}{*}{ Samples } & \multicolumn{7}{|c|}{ The Hazardous Parameters Radioactive } \\
\cline { 2 - 7 } & $\mathbf{R a}_{\text {eq }}(\mathbf{B q} / \mathbf{K g})$ & $\mathbf{D}_{\text {ap }}(\mathbf{n G y} / \mathbf{h})$ & $\mathbf{A E D}(\mathbf{m S v} / \mathbf{y})$ & $\mathbf{H}_{\text {ext }}$ & $\mathbf{H}_{\text {int }}$ & $\mathbf{I}_{\boldsymbol{\gamma}}$ \\
\hline H1 & $33.31 \pm 1.25$ & $16.34 \pm 0.16$ & $0.02 \pm 0.001$ & $0.09 \pm 0.02$ & $0.11 \pm 0.04$ & $0.12 \pm 0.005$ \\
\hline H2 & $30.22 \pm 2.12$ & $14.82 \pm 1.04$ & $0.02 \pm 0.001$ & $0.08 \pm 0.03$ & $0.10 \pm 0.01$ & $0.10 \pm 0.008$ \\
\hline H3 & $35.41 \pm 0.56$ & $17.35 \pm 0.28$ & $0.02 \pm 0.0004$ & $0.10 \pm 0.02$ & $0.12 \pm 0.002$ & $0.12 \pm 0.002$ \\
\hline H4 & $100.69 \pm 12.04$ & $51.90 \pm 6.25$ & $0.06 \pm 0.009$ & $0.27 \pm 0.05$ & $0.31 \pm 0.03$ & $0.39 \pm 0.050$ \\
\hline H5 & $41.83 \pm 0.37$ & $20.50 \pm 0.18$ & $0.03 \pm 0.0002$ & $0.11 \pm 0.03$ & $0.14 \pm 0.001$ & $0.15 \pm 0.001$ \\
\hline H6 & $37.68 \pm 1.89$ & $18.28 \pm 0.92$ & $0.02 \pm 0.001$ & $0.10 \pm 0.03$ & $0.13 \pm 0.01$ & $0.13 \pm 0.007$ \\
\hline H7 & $42.79 \pm 0.80$ & $20.73 \pm 0.38$ & $0.03 \pm 0.001$ & $0.12 \pm 0.03$ & $0.14 \pm 0.002$ & $0.14 \pm 0.003$ \\
\hline H8 & $140.26 \pm 6.55$ & $69.45 \pm 4.24$ & $0.09 \pm 0.01$ & $0.38 \pm 0.13$ & $0.45 \pm 0.05$ & $0.49 \pm 0.066$ \\
\hline H9 & $70.25 \pm 14.65$ & $34.10 \pm 2.02$ & $0.04 \pm 0.002$ & $0.19 \pm 0.06$ & $0.23 \pm 0.01$ & $0.19 \pm 0.016$ \\
\hline H10 & $49.71 \pm 2.05$ & $24.02 \pm 0.99$ & $0.03 \pm 0.001$ & $0.14 \pm 0.04$ & $0.17 \pm 0.01$ & $0.17 \pm 0.008$ \\
\hline H11 & $107.99 \pm 2.27$ & $52.34 \pm 1.10$ & $0.06 \pm 0.002$ & $0.29 \pm 0.08$ & $0.36 \pm 0.01$ & $0.37 \pm 0.009$ \\
\hline H12 & $124.96 \pm 8.12$ & $62.23 \pm 4.06$ & $0.08 \pm 0.006$ & $0.34 \pm 0.09$ & $0.40 \pm 0.02$ & $0.45 \pm 0.033$ \\
\hline H13 & $78.69 \pm 14.23$ & $40.61 \pm 7.43$ & $0.05 \pm 0.010$ & $0.21 \pm 0.05$ & $0.25 \pm 0.04$ & $0.31 \pm 0.060$ \\
\hline H14 & $35.25 \pm 1.57$ & $17.29 \pm 0.77$ & $0.02 \pm 0.001$ & $0.10 \pm 0.02$ & $0.12 \pm 0.01$ & $0.12 \pm 0.006$ \\
\hline Range & $30.22-140.26$ & $14.82-69.45$ & $0.02-0.09$ & $0.08-0.38$ & $0.10-0.45$ & $0.10-0.49$ \\
\hline Average & $66.36 \pm 9.89$ & $32.86 \pm 2.64$ & $0.04 \pm 0.003$ & $0.04 \pm 0.003$ & $0.22 \pm 0.02$ & $0.24 \pm 0.02$ \\
\hline
\end{tabular}




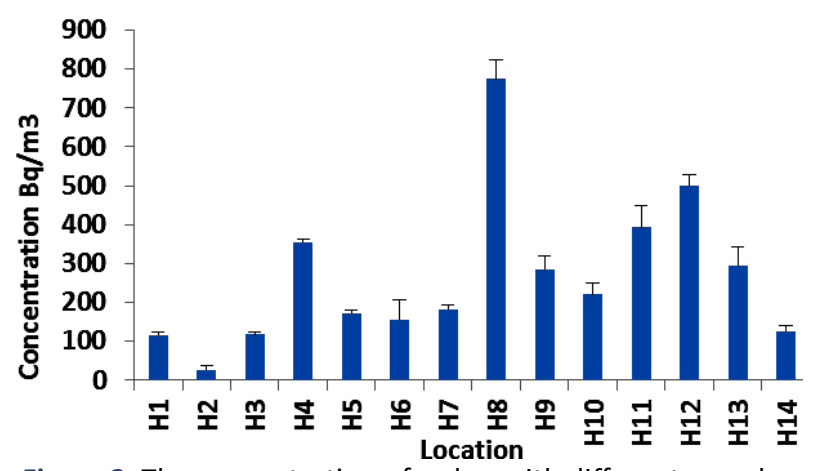

Figure 2. The concentration of radon with different samples by using CR39.

Table 3. Comparison of present study with mean value of radioactive concentration of Ra -226 , Th-232 and K-40 from other countries.

\begin{tabular}{|c|c|c|c|c|}
\hline \multirow{2}{*}{ Country } & \multicolumn{3}{|c|}{$\begin{array}{l}\text { Mean value of radioactive } \\
\text { concentration by (Bq/Kg) }\end{array}$} & \multirow{2}{*}{ References } \\
\cline { 2 - 4 } & ${ }^{\mathbf{2 2 6} \mathbf{R a}}$ & ${ }^{\mathbf{2 3 2}} \mathbf{T h}$ & ${ }^{\mathbf{4 0}} \mathbf{K}$ & \\
\hline Egypt & 13.04 & 12.33 & 445.33 & Present work \\
\hline Egypt & 35.17 & 25.66 & 187.30 & $(34)$ \\
\hline Egypt & 132.00 & 198.00 & 236.00 & $(35)$ \\
\hline Egypt & 11.30 & 9.83 & 411.32 & $(36)$ \\
\hline Egypt & 56.00 & 53.00 & 120.00 & $(37)$ \\
\hline Vietnam & 60.00 & 95.00 & 1073.00 & $(38)$ \\
\hline India & 8.00 & 25.00 & 275.00 & $(39)$ \\
\hline Turkey & 290.00 & 532.00 & 1160.00 & $(40)$ \\
\hline Saudi Arabia & 26.41 & 10.86 & 298.50 & $(16)$ \\
\hline Spain & 13.00 & 10.99 & 451.00 & $(41)$ \\
\hline Thailand & 12.00 & 19.00 & 344.00 & $(42)$ \\
\hline Brazil & 192.00 & 1673.00 & 217.00 & $(43)$ \\
\hline
\end{tabular}

\section{DISCUSSION}

\section{Characterization of gamma sources in the Wadi Hodein area}

Based on the results of the gamma ray measurements of the radionuclides emitted from the samples collected from Wadi Hodein. The results showed a difference in radioactivity based on the values of radioactive nuclei in the soil. It was found that the concentrations of naturally occurring radionuclides for ${ }^{226} \mathrm{Ra}$ and ${ }^{232} \mathrm{Th}$ were lower than the exemption level 32 and 45 , respectively. Regarding ${ }^{40} \mathrm{~K}$, the results showed higher values than the exemption levels which is 412 (7). Samples containing high values of ${ }^{40} \mathrm{~K}$ distributed along the valley were $(11,12$, $13,1,8)$. This indicates the diversity of the presence of radioactive nuclei in the valley and Int. J. Radiat. Res., Vol. 19 No. 3, July 2021

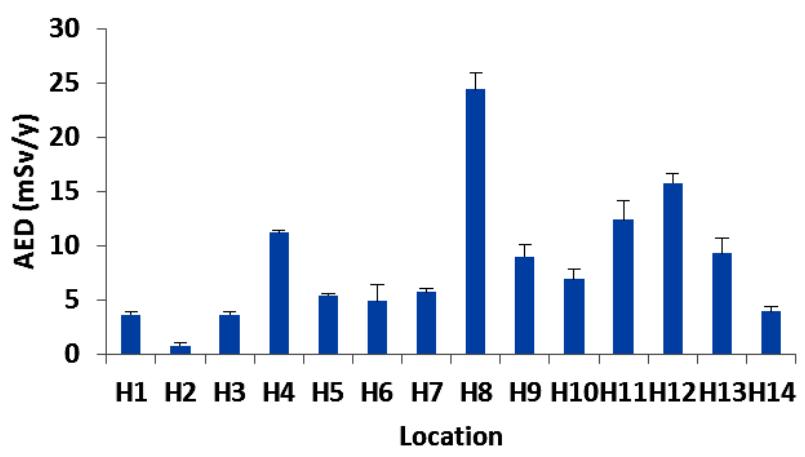

Figure 3. The annul effective dose with different location by using CR39.

Table 4. The exhalation rate for radon in soil, lung cancer cases per year per million person (CPPP) and the concentration of radium.

\begin{tabular}{|c|c|c|c|c|}
\hline \multirow{2}{*}{$\begin{array}{c}\text { The } \\
\text { Samples } \\
\end{array}$} & \multirow{2}{*}{$R a_{\text {eff }} \mathrm{Bq} / \mathrm{Kg}$} & \multirow{2}{*}{$\begin{array}{l}\text { Lung cancer } \\
/ 10^{6} \text { person }\end{array}$} & \multicolumn{2}{|c|}{ The exhalation rate* } \\
\hline & & & $E_{A} \mathrm{mBq} / \mathrm{m}^{2} \cdot h$ & $E_{m} \mathrm{mBq} / \mathrm{Kg} \cdot \mathrm{h}$ \\
\hline H1 & $10.05 \pm 0.67$ & $65.83 \pm 4.36$ & $11.87 \pm 0.79$ & $0.75 \pm 0.05$ \\
\hline $\mathrm{H} 2$ & $2.28 \pm 0.83$ & $14.92 \pm 5.41$ & $2.69 \pm 0.98$ & $0.17 \pm 0.06$ \\
\hline H3 & $10.17 \pm 0.55$ & $66.60 \pm 3.60$ & $12.01 \pm 0.65$ & $0.75 \pm 0.04$ \\
\hline H4 & $30.78 \pm 0.67$ & $201.61 \pm 4.36$ & $36.35 \pm 0.79$ & $2.28 \pm 0.05$ \\
\hline H5 & $14.96 \pm 0.55$ & $97.98 \pm 3.60$ & $17.67 \pm 0.65$ & $1.11 \pm 0.04$ \\
\hline H6 & $13.47 \pm 4.38$ & $88.21 \pm 28.70$ & $15.90 \pm 5.17$ & $1.00 \pm 0.32$ \\
\hline H7 & $15.86 \pm 0.97$ & $103.89 \pm 6.34$ & $18.73 \pm 1.14$ & $1.18 \pm 0.07$ \\
\hline H8 & $67.10 \pm 4.32$ & $439.49 \pm 28.29$ & $79.25 \pm 5.10$ & $4.98 \pm 0.32$ \\
\hline $\mathrm{H9}$ & $24.74 \pm 2.99$ & $162.01 \pm 19.60$ & $29.21 \pm 3.53$ & $1.83 \pm 0.22$ \\
\hline H10 & $19.12 \pm 2.59$ & $125.24 \pm 16.97$ & $22.58 \pm 3.06$ & $1.42 \pm 0.19$ \\
\hline H11 & $34.08 \pm 4.91$ & $223.21 \pm 32.12$ & $40.25 \pm 5.79$ & $2.53 \pm 0.36$ \\
\hline $\mathrm{H} 12$ & $43.47 \pm 2.26$ & $284.68 \pm 14.80$ & $51.33 \pm 2.67$ & $3.22 \pm 0.17$ \\
\hline H13 & $25.64 \pm 3.92$ & $167.93 \pm 25.66$ & $30.28 \pm 4.63$ & $1.90 \pm 0.29$ \\
\hline H14 & $10.99 \pm 1.28$ & $72.00 \pm 8.40$ & $12.98 \pm 1.51$ & $0.82 \pm 0.10$ \\
\hline
\end{tabular}

their lack of concentration in one region. The valley contains multiple activities, including agricultural, industrial and residential, so any increase in the level of radiation is of great importance in preserving the environment.

The obtained results showed that the average dose of absorbed gamma emitted from soil in Wadi Hodein region contains values higher than the permissible international value (i.e. $57 \mathrm{ng} /$ hour) (7) due to the presence of high levels of radionuclide concentration in the soil. Samples containing high doses are $(11,12,4,8)$, while the sample (13) value was high, but less than permissible. This leads to increased radiation doses towards the public and workers in the valley.

Regarding the average value of the external risk index $\left(\mathrm{H}_{\mathrm{ex}}\right)$, the internal risk index $\left(\mathrm{H}_{\text {in }}\right)$ and 
the representative gamma index (I $\gamma)$, the results showed that it was less than one in all samples. This gives the risk rates of gamma in the region safe for workers.

\section{Characterization of radon in the Wadi Hodein area}

The amount of radon concentration in the environment depends on the concentration of radionuclides generated from natural sources as well as the permeability of the soil. The results shown in figure 2 showed that the samples $(4,8$, 11 and 12) contain high levels of radon. These samples are found in different places in the valley. This means that the possibility of large amounts of radon along the valley is very large, which leads to exposure of workers and residents to high levels of radon gas. The results are consistent with the concentration values of radioactive nuclei ( $\mathrm{U}, \mathrm{Th}, \mathrm{Ra})$. This means that the radon values depend not only on uranium but also with the values of other radioactive nuclei that cause its presence. The results also showed that the values measured with CR-39 were more consistent with the values of the concentrations. Therefore, CR-39 is more accurate in determining and monitoring radon values. Regarding the radiation dose, it was consistent with the radon values that were measured, and this is illustrated in figure 3. The high levels of the radiation dose make the necessity of pursuing research in the Wadi Hodein necessary for maintaining health and the environment.

\section{CONCLUSION}

The results show that $62.5 \%$ of the radon gas concentrations and AED in soil was below the allowed limit recommended by (ICRP) agency which is $\left(200 \mathrm{~Bq} / \mathrm{m}^{3}\right.$ and $\left.3-10 \mathrm{mSv} / \mathrm{y}\right)$ respectively. There was a significant correlation between increasing the annual absorbed dose of radon and digestive and respiratory cancer. This relationship was observed between calculated dose values (CPPP) and radon gas concentration in the samples.
Conflicts of interest: Declared none.

\section{REFERENCES}

1. Shabaan DH and Al-Nagaar TI (2019) Improvement in optical properties of nuclear track detector. Nuclear science. Special Issue: Radiation Dosimeter, 4: 23-26.

2. Al-Nagaar TI and Doaa SH (2018) Simple analysis of radioactivity, and assessment of radiological hazards in different types of household foods. International Journal of Recent Scientific Research, 9: 24838-24843.

3. Karim MS, Abdullah MH, Abass WH (2012) Measurement of Radon Gas Concentration in Cement Samples by Using Nuclear Track Detector (CR-39) Diyala Journal for Pure Sciences, 8: 2222-8373.

4. Entesar H, EL-Araby, Soliman HA, Abo-Elmagd M (2019) Measurement of radon levels in water and the associated health hazards in Jazan - Saudi Arabia. Journal of Radiation Research and Applied Science, 12: 31-36.

5. Bistra Kunovska, Kremena Ivanova, Zdenka Stojanovska, et al. (2013) Measurements of Radon Concentration in Soil Gas of Urban Areas. Bulgaria Rom Physics, 58: 172-179.

6. Hesham A Youssef, Embaby AA, El-Farrash AH, et al. (2015) Radon exhalation rate in surface soil of graduates' villages in west Nile Delta, Egypt using Can Technique. Int J Recent Scientific Research, 6: 3440-3446.

7. UNSCEAR (2008) United Nations Scientific Committee on the Effects of Atomic Radiation Sources and Effects of Ionizing Radiation. United Nations Publication Annex B.

8. UNSCEAR (2000) United Nations Scientific Committee on the Effects of Atomic Radiation Sources and Effects of Ionizing Radiation. United Nations Publication.

9. El-Badry BA, Al-Naggar TI, Khouqeer GA (2020) Monitoring the levels of radon and toxic elements pollutants in bottled drinking water. Int J Radiat Res, 18: 427-435.

10. HPA (2009) Radon and public health. Report of the Independent Advisory Group on lonising Radiation, June.

11. Kovacs T, Szeiler G, Fabian F, et al. (2013) Systematic survey of natural radioactivity of soil in Slovenia. J Environ Radiocast, 122: 70-78.

12. Bala P, Mehra R, Ramola RC (2014) Distribution of natural radioactivity in soil samples and radiological hazards in building material of Una, Himachal Pradesh. Journal of Geochemical Explorer, 142: 11-15.

13. Forkapic S, Maleti D, Vasin J, et al. (2017) Correlation analysis of the natural radionuclides in soil and indoor radon in Vojvodina, Province of Serbia. Journal of Environment Radioactivity, 166: 403-411.

14. Carvalho C, Anjos RM, Veiga R, et al. (2011) Application of radiometric analysis in the study of provenance and transport processes of Brazilian coastal sediments. Environment Radioactivity, 102: 185-192.

15. Taher A, Alshahri F, Elsaman R (2018) Environmental impacts of heavy metals, rare earth elements and natural radionuclides in marine sediment from Ras Tanura, Saudi

Int. J. Radiat. Res., Vol. 19 No. 3, July 2021 
Arabia along the Arabian Gulf. Applied Radiation Isotope, 132: 95-104.

16. Sulekha N, Segunpta D, Guin R, et al. (2009) Natural radioactivity measurements in beach sand along southern coast of Orissa Eastern India. Environ. Earth Sci, 59: 593-601.

17. Ribeiro FCA, Silva JIR, Lima ESA, et al. (2018). Natural radioactivity in soils of the state of Rio de Janeiro (Brazil): radiological characterization and relationships to geological formation, soil types and soil properties. J Environ Radioact, 182: 34-43.

18. Bangotra P, Mehra R, Jakhu R, et al. (2019) Estimation of ${ }^{222} \mathrm{Rn}$ exhalation rate and assessment of radiological risk from activity concentration of ${ }^{226} \mathrm{Ra},{ }^{232} \mathrm{Th}$ and ${ }^{40} \mathrm{~K}$. Geochem Explor, 184: 304-310.

19. Elaraby EH (2018) Direct measurement of the radioactive radon gas activity in water in Saudi Arabia. AIP Conference Proceedings, 020019.

20. Zarrag Al-Fifi, Entsar H El-Araby, Hanan Elhaes (2012) Monitoring of Radon Concentrations in Jazan Beach Soil. Journal of Applied Sciences Research, 8: 823-827.

21. Hamza VZ and Mohankumar MN (2009) Cytogenetic damage in human blood lymphocytes exposed in vitro to radon. Mutation Research, 661: 1-9.

22. Rahaf A Aseeri, Aliya A Arishi, Entesar H Elaraby (2018) Estimation of primeval radio nuclei concentration in soil in Jazan region. AIP Conference Proceedings, (1), 020033.

23. Abdalsattar Kareem Hashim, Laith Ahmed Najam (2015) Radium and Uranium Concentrations Measurements in Vegetables Samples of Iraq. Detection, 3: 21-28.

24. Entesar H Elaraby (2013) Environmental Air Dosimetry in Some locations of Gazan Using Passive Track Detectors. Journal of life sciences and Technologies, 1: 75-78.

25. ICRP (2009) International Commission on Radiological Protection Statement on Radon. ICRP, Ref, 00/902/09.

26. Ismail AH and Jaafar MS (2010) Indoor Radon concentration and its Health Risks in Selected Locations in Iraqi Kurdistan using CR-39 NTDs. Bioinformatics and Biomedical Engineering (iCBBE), ldo 4th international Conference in Cheng du, 18-20.

27. El-Taher A, Makhluf SA, Nossair, Abdel S, et al. (2009) Assessment of natural radioactivity levels and radiation hazards due to cement industry. Applied Radiation Isotope, 68: 169-74.

28. Beretka J and Mathew PJ (1985) Natural radioactivity of Australian building materials, industrial wastes and byproducts. Health Phys, 48: 87-95.

29. European Commission EC (2000) Report on Radiological Protection Principles Concerning the Natural Radioactivity of Building Materials. Radiation Protection, 112.

30. ICRP (2007) radiological protection in medicine. ICRP Publication 105. Ann. ICRP 37 (5).

31. ICRP (1993) Protection against Rn-222 at home and at work. International Commission on Radiological Protection Publication 65. Ann. ICRP 23 (2). Pergamon Press, Oxford.

32. Vikas D, Asha R, Rohit M, Rakesh CR (2013) Assessment of natural radioactivity levels and associated dose rates in soil samples from Northern Rajasthan, India. Radiation Protection Dosimetry, 158: 235-240.

33. Ali K, Alsaedi B, Almayahi A, Alasadi AH (2013) Cement 222Rn and 226Ra Concentration Measurements in Selected Samples from Different Companies. Asian Journal of Natural and Applied Sciences, 2: 195-200.

34. Nada A, Ragab FM, Hosnia M Abu-Zied, Mostafa M (2018) Assessment of Radioactivity in Various Types of Soil From Al-Obour City, Egypt. Journal of Advances in Physics, 14: 5420-5434.

35. Hilal MA and Borai EH (2018) Hazardous parameters associated with natural radioactivity exposure from black sand. Regulatory Toxicology and Pharmacology, 92: 245-250.

36. Antar B and Eman S (2014) Mineralogical studies and evaluation of natural radioactivity in the stream sediments of Hadarba area, South Eastern desert, Egypt. Middle East Journal of Applied Sciences, 4: 855-865.

37. Samia ME, Nadia WE, Fawzia A, Amany S, Mahitab MAA (2005) Natural activity concentrations for selected kinds of Egyptian sand. Isotope Environment Health Study, 41: 161 $-168$.

38. Thua NPH, Thang VN, Loana TTH, Dong NV, Haoa LC (2019) Natural radioactivity and radon emanation coefficient in the soil of Ninh Son region, Vietnam. Applied Geochemistry, 104: 179-183.

39. Ramasamy M, Senthil, Meenakshisundaram V, Gajendran $V$ (2009) Measurement of natural radioactivity in beach sediments from north east Coast of Tamilnadu India. J Radiat Res and Appl Sci, 1: 54-58.

40. Orgun Y, Altnsoy N, Sahin SY, Gungor Y, Gultekin AH, Karahan G, Karaclk Z (2007) Natural and anthropogenic radionuclides in rocks and beach sands from Ezine region (Çanakkale), Western Anatolia, Turkey. Applied Radiation Isotope, 65:739-747.

41. Casas-Ruiz M, Ligero RA, Barbero L (2012) Estimation of annual effective dose due to natural and man-made radionuclides in the metropolitan area of the Bay of Cadiz (SW of Spain). Radiation Protected Dosimetry 150: 60-70.

42. Malain D, Regan P H, Bradley DA, Matthews M, Santawamaitre T, Al-Sulaiti HA (2010) Measurements of NORM in beach sand samples along the Andaman coast of Thailand after the 2004 tsunami. Nuclear Instruments Methods A, 619: 441-445.

43. Veiga R, Sanchez N, Anjos R M, Macario K, Bastos J, Iguatemy J G, Aguiar J G, Santos A M, Mosquera B, Carvlho C (2006) Measurement of natural radioactivity in Brazilian beach sands. Radiation Measurement, 41: 189-196. 
